\title{
Understanding Material vs. Immaterial in Conceptual and Digital Art
}

\section{Resceturdi Avtichlas}

\section{Rahma Khazam}

In the history of twentieth-century art, we can identify two key episodes when the notion of the immaterial became a focus of attention. The first, spanning the period from the mid-1960s to the mid-1970s, occurred in the context of conceptual art, and was famously described in Lucy Lippard's Six Years: The Dematerialization of the Art Object from 1966 to $1972 .{ }^{1}$ The second, still ongoing, is associated with digital art, a term first used in the 1980s that refers to work employing digital technology - whether as a tool for reworking traditional media or as a means of creating new wholly digital artforms such as net-art. ${ }^{2}$ Yet although conceptual and digital art both failed to live up to the claim of immateriality, new evanescent kinds of materiality nonetheless emerged in their wake, as I will argue in the two parts of this essay.

In the first part I will show that despite the discourse about dematerialization, some of the key protagonists of conceptual art, from Mel Bochner to Robert Barry and Robert Morris, nonetheless evinced an interest in materiality - a claim borne out by their own statements and practices and by a recent conference on the topic of materiality and conceptualism that challenged the latter's reputation as idea-centred. ${ }^{3}$ Yet conceptual art, despite failing to attain immateriality, nonetheless changed the way we consider materiality, paving the way for the new approaches that were to be facilitated by digital technology. In the second part, I will show that digital art, despite its supposed immateriality, is also a material enteprise, as borne out by the work of a number of artists and theorists from James Bridle to Ber- nard Stiegler. The immateriality of digital artworks has furthermore been challenged on the grounds that the infrastructure and tools required to produce and maintain them are firmly grounded in the physical world. While the first part of this essay explores the shift from dematerialization back to the material in the context of conceptual art, the second highlights the analogous developments that are still taking place in digital art, my aim being to map the similarities between these two tendencies. As I will suggest, they both tried - but failed - to satisfy art's recurring but unrealizable yearning to rid itself of the material: as it turned out, the material could not be eliminated, but only made, so to speak, less material.

Before that however, it is necessary to define the terms digital/conceptual and material/immaterial as they are used in the two parts of this essay. As suggested in the pre- 
vious paragraph, the terms digital and conceptual art do not refer so much to stable or bounded art movements but are tendencies, loose categorizations that group together very different works and approaches. Digital art came about in the wake of the gradual digitalization of society as a whole since the 1990s and ranges from electronic music and digital photography to computer-generated paintings and traditional artworks incorporating some form of digital technology. Conceptual art is even harder to pin down, referring as it does to work in which the idea is more important than technical or formal considerations: when it emerged in the 1960s, it included not only video and performance but also photography, narrative and actions. ${ }^{4}$ That said, individual artworks that question the importance of physical objects or incorporate digital technology can nonetheless be explored and evaluated in terms of the different kinds of materiality they generate, as I plan to do here.

The material/immaterial binary can also be understood in different ways. In the first part of this essay, immaterial refers to dematerialization, as defined by Lucy Lippard in her book Six Years. She writes: "Concep- tual art, for me, means work in which the idea is paramount and the material form is secondary, lightweight, ephemeral, cheap, unpretentious and/or 'dematerialized'". ${ }^{5}$ I will contrast Lippard's use of the term dematerialization with the different kinds of materiality explored by artists of that time, such as that of invisible materials such as air, gases or radiation. In the second part, immaterial will refer to art that uses digital technology, whether as a tool or as a means of creating new artforms. ${ }^{6}$ Immaterial in the sense of art made wholly or entirely with technological means will be contrasted with the various kinds of materiality that may be associated with digital art - these include the sensuous or tactile aspect of the technology and the materiality of the interface or medium as well as more theoretical approaches to materiality such as Christiane Paul's concept of neomateriality. Both parts of the essay will refer to artworks that expand the limits of materiality, allowing us to understand the term as "a potential predisposed for continuous conceptual recoding, reorganisation, redistribution, recontextualisation and reinterpretation", as Jacob Lillemose suggests. ${ }^{7}$

My essay will furthermore emphasize the commonalities between these two episodes when the notion of the immaterial was - and in the case of digital artworks still is - being eclipsed by that of the material. Scholars tend to focus on the shift back to the material in one or the other field, without paying sufficient attention to the parallels between them. This is a gap I hope to fill. It could be objected that digital art cannot be compared to conceptual art, because digital technology is merely a tool, whereas conceptual art is an art movement. However, this assumption is false: as indicated above, neither is a movement as such, although individual digital and conceptual artworks can nonetheless be compared in terms of the type of materiality they generate. My contribution to the question of material/immaterial in conceptual and digital art will be to highlight the connections not only between these two artistic tendencies, but also between the concepts of material and immaterial, and thereby open up new lines of debate.

\section{PART I: Conceptual Art}

The notion of dematerialization, as expounded by Lucy Lippard, was to have a decisive impact on conceptual art, by endowing it with an immaterial dimension. Referring to 
the emergence of an art that foregrounds the thinking process, she wrote: "Such a trend appears to be provoking a profound dematerialization of art, especially of art as object, and if it continues to prevail, it may result in the object's becoming wholly obsolete." With regard to conceptual art's genealogy, Lucy Lippard recognized Cage, Duchamp and Dada as precursors but, as Christian Berger points out, she omitted the rich pre-history of dematerialization in the work of early twentieth-century abstract artists such as Kandinsky. ${ }^{9}$ The linguistic metaphor inherent in Kandinsky's visual language of form and colour was subsequently assimilated in the language-based conceptual art of the 1960s in the work of artists such as Joseph Kosuth.

However Lippard's claims soon turned out to be unfounded: in an unpublished letter-essay from 1968, Art \& Language pointed out that the art objects to which she was referring were merely replacing matter in its traditional state with matter in a gaseous or liquid state. ${ }^{10}$ In Six Years, Lippard admitted that since she first addressed the issue in 1967, she had often been told that the term dematerialization was incorrect and that "a piece of paper or a photograph is as much an object, or as 'material', as a ton of lead. Granted. But for lack of a better term I have continued to refer to a process of dematerialization, or a deemphasis on material aspects". ${ }^{11}$ The art world too continued to refer to it, and indeed, as Owen Duffy points out, it has since "matriculated into art historians' lexicons, as well as the annals of art history. Through dematerialization, the critics believed art might escape commodification because dealers could not sell art-as-idea."12

Any counter-claim to the effect that conceptual artists were interested in materiality has to contend with this history and the misconceptions to which Lippard's notion of dematerialization has given rise. In this essay, I make such a counter-claim by arguing that the discourse on dematerialization, the shift from material to immaterial to which it points, was soon followed by another equally important shift, from dematerialization back to the material. It is this second shift that I will focus on here, as reflected in the work of those artists whose practices came to epitomize dematerialization but who, as it turned out, were more interested in exploring the material and the different forms it could take.
Take the conceptual artist Mel Bochner, whose work investigates the gap between reality and the way we analyze or seek to rationalize it. The importance of materiality in Bochner's work is borne out by Mark Godfrey, who in his book Abstraction and the Holocaust, points out: "Bochner never denied the materiality of his works, and this is another reason why he resisted labels like 'dematerialisation' or 'conceptual art'. It was precisely the materiality of the work that counted [...], but the materials would be expedient and provisional."13 Bochner's materials included paper, masking tape, chalk and matches, but rather than referencing Arte Povera, it was rather, as Godfrey states, the feeling of vulnerability that was key:

Bochner's was a provisional, fragile materiality that embodied doubt and his hesitancy to make anything permanent and monumental. In short, Bochner's approach to materials was absolutely intertwined with his acknowledgement of a post-Holocaust cultural and epistemological landscape where all certainties were shattered. ${ }^{14}$

Further confirmation of Bochner's interest in materiality comes from the artist himself. As he pointed out in a recent interview, the notion of conceptual art as idea-centred caused considerable confusion by suggesting that

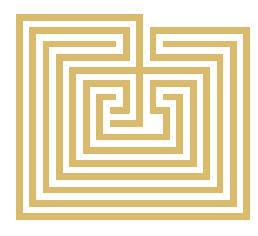


art did not require a physical or visual form of expression - even though this was impossible. As for the term idea, it was hard to know exactly what it meant, and indeed, he preferred such terms as intuition or hunch. ${ }^{15}$ Clearly, art is always propelled by some kind of intuition and always has some kind of material substrate: even in the case of the spoken word, there is a record of its existence.

Other works of Bochner's display a different, more evanescent kind of materiality linked to tangibility or a lack thereof. Speaking at the symposium "Mel Bochner on Translation" (Centre Georges Pompidou, Paris, 6 and 7 December 2019), Larisa Dryansky explored the troubling, indefinable tangibility of these pieces: Transparent and Opaque (1968-1998), a set of prints in which glass plates were thickly coated with shaving cream or vaseline and photographed under coloured lights, stimulated the viewer's sense of touch, while Actual Size (Hand) (1968), a 1:1 photograph that juxtaposed the artist's hand with a measurement on a wall, commented on the gap between tangibility and abstraction. Nina Leger, another speaker at the symposium, addressed Bochner's explorations of the shift from three to two di- mensions, as in the case of a photographed object, investigating the losses and gains thereby engendered. As she showed, the loss of materiality led not so much to immateriality as a renewed interest in materiality, a materiality that was no longer tangible but present as a lack.

Robert Barry's name is often cited in connection with dematerialization, on account of his use of invisible materials, such as electromagnetic waves, ultrasonic sound, microwaves and radiation. Yet his aim was to use them like other materials, by detecting and measuring them, and exploring their physical existence. As he stated on the occasion of "January 5-31 1969", an exhibition organized by Seth Siegelaub in New York: "These forms [...] exist, they [...] have their own characteristic. They are made of various kinds of energy [and] I use various devices to produce the energy [...] and define its form." 16

The works of Robert Morris also question the idea of dematerialization, emphasizing material processes instead. A conceptual artist who was also a leading protagonist of Minimalism and process art, Morris followed up his stripped down Minimalist plywood forms of 1964 with pieces such as Untitled (Pink Felt) (1970). Its pieces of pink industrial felt eschewed questions of form, having been simply dropped on the ground. The interest in the object had shifted to a fascination for handling materials, as the editors of Art in Theory point out with respect to the work of Morris and others: "A materialism focused on the processing of mute stuff turned the hyper-formalism of the Minimalist object into 'anti-form': a materialism reminiscent of nothing so much as Bataille's earlier valorization of the 'informe'. Attention turned towards 'making': a concern with processes of manipulation of materials." ${ }^{17}$

More recently, the conference "Conceptualism and Materiality. Matters of Art and Politics", held at the Courtauld Institute of Art in London on 10-11 October 2019, shed new light on the key contribution of materials and materiality to conceptual art, constituting a valuable source of information on the topic. The conference challenged, on several different fronts, the view that the conceptualism of the 1960s and 1970s was an idea-centred, non-materialist undertaking. Its organiser, Christian Berger, rightly emphasized that virtually none of the artists concerned applied 
the term "dematerialization" to their practice, and indeed, for the majority of them, getting away from materials had not been a key preoccupation: Robert Barry, for instance, referred to radio waves as an "incredible material". ${ }^{18}$ Yet the materials and techniques used by conceptual artists nonetheless countered established notions of objecthood, as Berger pointed out: "While conceptual art's in many ways inconsistent and incomplete attempts towards a reconsideration of the object character of art did not result in a fundamental transformation of art's commodity status, they did challenge capitalist systems of exchange through their critique of objecthood."19

Likewise discussed at the conference, Michael Asher's air works were a prime example of how invisible materials can have a material dimension. In the late 1960s, Asher used air blowers to create fields of air, spaces whose limits, as speaker Kavior Moon stressed, could be experienced by entering or exiting them, thereby endowing form with a new kind of materiality. The air works were moreover installed as carefully and precisely as any other art material. For Moon, Asher's air works were all the more material in that they prodded the viewer "into perceiving the work's surrounding context, that is, all of the material conditions needed to produce it". ${ }^{20}$ Larisa Dryansky, another speaker at the conference, sought to get around the material/ immaterial binary shaping the discourse on conceptual art by proposing a third term that would take both extremes into account. She discussed the notion of antimatter, whose sub-atomic particles have properties that are opposite to those of normal matter, noting that it appealed to artists such as Robert Smithson and Mel Bochner, because of the lingering materiality it evoked. ${ }^{21}$ Finally, Niko Vicario looked at the use of teletype machines between the years 1966 and 1970 by artists such as Hans Haacke. He showed how they linked different sites and brought the outside world into the exhibition space, thereby blurring the divisions between material, immaterial, dematerialization and rematerialization. ${ }^{22}$ Like the other speakers, he underscored the emergence of new and different kinds of materiality, whether invisible, intangible, or redefined as antimatter.

In other words, while there was certainly a renewed emphasis on materiality in reaction to Lippard's claim of dematerialization, in the form of a shift from the immaterial back to the material - the material that was being newly attended to was not the same as before. The above-mentioned works by Bochner, Barry, Morris, Haacke and Asher all confirm that a new and expanded understanding of materials and materiality was being forged in the practice of artists of that time, a materiality that was no longer linked to bounded physical objects as such. Nor were these artists associated with conceptual art the only figures from that period whose work may be regarded as rethinking the meaning of materiality. Jacob Lillemose gives the example of the list of verbs that Process Art exponent Richard Serra drew up in 1967 and 1968: comprising verbs such as to roll, to crease, to fold, etc., the list testifies to an interest in manipulating and redistributing materiality, reflected in the lead works Serra was making at around the same time. As Lillemose states, with reference not only to Serra but also to works by Robert Smithson and Gordon Matta-Clark: "By displacing the industrial materials from their usual functionalistic and rationalistic contexts, these artists set materiality in general free from the stable object and placed it into fluid, fluctuating and expressive relations." ${ }^{23}$ 
The claim of immateriality thus proved unfounded, but did give rise to a new more evanescent kind of materiality. Indeed, this new, fluid materiality that had been set free from the stable object was largely migrating into systems, mirroring the shift from object to system under way in culture as a whole. As Jack Burnham famously observed: "We are now in transition from an object-oriented to a systems-oriented culture. Here change emanates, not from things, but from the way things are done."24 For Lillemose, Hans Haacke's work with teletype machines epitomized this transformation. In Haacke's News (1969), information from local, national or international news services was printed out in real time in the exhibition, showing that the white cube was not isolated from the world but very much bound up with larger systems beyond it, whether economic, political or social: Haacke's works exposed these systems, making their workings and implications visible. ${ }^{25}$

Other works of conceptual art also pointed towards these larger systems, which were more than just abstract networks bereft of any impact, but could have material effects on people's emotions, actions and behav- iour. In particular, systems generated affects - which for Gilles Deleuze relate to embodied experience and bodily intensities and for this reason may likewise be understood as material in an expanded sense. In her book Systems We Have Loved, ${ }^{26}$ Eve Meltzer shows how conceptualism and structuralism were both bound up with systems, and how affect was the means artists used to liberate themselves from their dryness and rigour. An especially striking example of how bodily, and therefore material, intensities and affects could attenuate the rigour of systems, is conceptual artist Mary Kelly's Post-Partum Document (1973-79), an extensive exploration of the mother-child relationship. Each part of the work concentrates on a key moment in the acquisition of language by the artist's son as well as the artist's ensuing sense of loss, as seen from the perspectives of the mother, the child and an external observer. As Meltzer observes: "[W]hile Mary Kelly [...] quotes furiously from a range of critical discourses, deploying diagrams, schemas, and theoretical apparatuses over and over again, Post-Partum Document in fact demonstrates that even the most 'arbitrary' of signifiers can become cathexes for affect and invest- ment." ${ }^{27}$ Whether in radio waves or more abstract notions such as systems and affect, new and untoward types of materiality kept recurring in conceptual art.

The new materiality was thus freeing itself from traditional sculptural and artistic forms: the rationalist, quasi-scientific approach observable in works such as Mary Kelly's resonated to a greater extent with Jack Burnham's preoccupations in his book Beyond Modern Sculpture: The Effects of Science and Technology on the Sculpture of This Century. As Burnham wrote: "[M]uch of the most contemporary and provocative three-dimensional art is only generically related to the figurative sculpture of the past. Recent modes, particularly Kinetic, Luminous, and Environmental Art, are all stuffed uneasily under the category of sculpture, but as yet they are too problematic to be classified." ${ }^{28}$ For Burnham, the impetus that was now driving sculpture was clearly elsewhere, sketched out in his book's subtitle, The Effects of Science and Technology on the Sculpture of This Century. He wrote: "The subtitle of this book may appear to limit its scope; however, I feel that it covers the prime controlling forces of modern sculpture." ${ }^{29}$ Burnham's belief that tech- 
nology would redefine art was epitomized by conceptual art, to the point where, as Lillemose writes, it was "metaphorised by Burnham as software". ${ }^{30}$ There were of course major differences in background, methodology, motivations and approach between conceptual art and digital technology, yet acknowledging their common interest in notions such as systems opens up a new and more exhaustive reading of the history of art, as Edward Shanken points out: "Such a history will acknowledge cybernetics, information theory and systems theory as foundational intellectual models that, in combination with the advent of digital computing and telecommunications, played a significant role in shaping culture." ${ }^{31}$

That conceptual art must be seen against this broader background of technological progress is likewise emphasized by Owen Duffy, who regards "The Dematerialization of Art' as a signpost that constellates a much larger ideology of dematerialization". ${ }^{32}$ For Duffy, dematerialization was part and parcel of culture in the 1960s, and it still is today, insofar as we are immersed in technologies such as the internet that many of us still believe to be immaterial. There was indeed an interest in materiality in the work of Bochner et al., but theirs was to a large extent an evanescent materiality that, like the culture of their time, could not conceal its fascination with the immaterial.

\section{PART II: Digital Art}

A similar shift from the immaterial back to the material may also be observed in the discourse around digital art. As mentioned earlier, digital art is a loose term for all kinds of art using digital technology. Digital artforms, whether photography or video, were initially hailed as embodying the shift from the material to the immaterial, until it began to be acknowledged that they necessarily have a material substrate of some kind, whether data centres, screens or underground cables - a substrate that is essential to their functioning and therefore irreplaceable, unlike the canvas, frame or plinth.

Just as both tendencies failed to achieve immateriality, so have they also engendered new, more evanescent forms of materiality. In the case of digital artworks, these extend from works exploring the materiality and tactility of the digital medium, to pieces foregrounding the user's bodily experience, through to theoretical redefinitions of the term. The materiality of the medium is explored by the New Aesthetic, as the artist James Bridle dubbed it in 2011: in reaction to the ubiquity of digital media, the New Aesthetic sought to orchestrate a return to materiality by making the digital visible in the physical world, thereby achieving, as Michael Betancourt puts it, the "physicalization of what was/is more commonly purely digital - a realization of immateriality as physicality". ${ }^{33}$ Examples include the pixelization aesthetic in art and fashion, where a unit that belongs not to the real world but to the digital realm, is made visible in our world. ${ }^{34}$ An artwork that illustrates this shift from the immaterial back to the material is Bartholomäus Traubeck's Perspective and Projection (2009-present). Here, the artist presents satellite images taken from Google Earth's database, deliberately selecting shots whose subject-matter is unrecognizable. Commenting on these images, in which the gaze of the machine can be seen to offer a very different vision of the world from the human one, Daniëlle de Jonge observes: "These 'new eyes' seem to have their own rules and their own grain and aesthetic." ${ }^{35}$ 
The seemingly autonomous materiality of machines was also to the fore in the exhibition "Geographies of Contamination", held at DRAF, London in 2014. Referencing the New Aesthetic, it set out to survey the return to materiality in art practice, a materiality described in the curatorial statement as marked by "the paradoxes of 'immaterial physicality' and of impersonal subjectivity in contemporary culture". ${ }^{36}$ Exploring the workings of systems and processes, it featured artists such as Renaud Jerez and David Douard, who commented on the escalating presence of machines in our daily lives by creating hybrid digital and mechanical environments made up of computer animations, films, soundtracks, and everyday or motorized objects. Highlighting the dynamics of hybridization and contamination between virtuality and reality, their works generated an elusive digitalized materiality.

Whereas these artists foreground the capabilities of machines above and beyond human perception or experience, other artists using digital technology underscore the connections between humans and machines. As opposed to exploring the materiality of the digital medium, as in the previous ex- amples, the focus here is on another kind of materiality, the bodily experience of the human engaging with the machine, whether the user, the viewer or even the artist. Jeff Elrod for example, transposes digital renderings onto canvas using manual techniques such as acrylic or spray paint. By physically imitating digital techniques, he reverses the hierarchy between humans and machines. Wade Guyton's works foreground a less physical and more cerebral relationship to machines. Guyton prints his paintings on sheets of linen that he runs through digital inkjet printers, producing streaks, misalignments and other flaws that affirm the proximity of machines and humans on a more abstract level than imitation: inkjet printing is a continuation of mechanical - and therefore analogue - reproduction technologies, while the streaks and misalignments point to digital technology's human-like capacity for error - and to its material effects. As in Elrod's case, the work generates a hybrid materiality, derived from the entanglements between humans and machines.

In his article "Surface, Image, Reception: Painting in a Digital Age", the art historian Alex Bacon comments on the new hybrid material practices associating humans and machines. He accounts for digital technology's seamless integration into such quintessentially material practices as painting by the fact that artists, as much as viewers, look, think and act today in ways that are shaped and prompted by technology. ${ }^{37}$ This state of affairs is considerably helped along by the resemblance between the canvas and the flatscreen, which allows painting to expand its range of concerns beyond the medium as such and shift the focus to yet another kind of materiality, the technology's sensuous or tactile aspect: as Bacon points out, the marks that Ken Okiishi paints on flatscreens recall not only Abstract Expressionism but also the traces that people's fingers leave on touchscreens. The distinctive tactile and material dimension of Okiishi's works is epitomized by gesture/title (2013), which consists of five painted monitors, whose screens Okiishi painted while showing videos on them.

However for Bacon the main question facing painting today is that of the materiality of the medium, particularly as expressed in the conflict between object and image, material and immaterial, and the question as to whether painting can simultaneously be 
both. ${ }^{38}$ Travess Smalley, for instance, creates physical versions of his screen-based works in order that the viewer might walk around them, rather than having to zoom in and out of an image on a screen. ${ }^{39}$ Yet although it is the same work that is physical and screen-based, in practice they have become two separate pieces, with each version provoking a different reaction in the viewer. Another work Bacon cites, Parker Ito's The Agony and the Ecstasy (2012), takes a more radical approach to the question, by literally blurring the boundaries between painting and image. In Ito's case, the details of the work are only visible when lit up by a flash, and so only when the work is on the way to becoming an image. Yet its reflective surface makes it difficult to photograph properly, all the more so as different brands of flash produce different results. It thus resists being viewed like a painting or photographed by a camera, thereby questioning the modus operandi of both. As Bacon writes: "In this way Ito is able to masterfully subvert the modernist insistence on the primacy of a painting's materiality as well as the more recent imperative for work to circulate freely in jpeg form [...] Somehow the work is about this relay between the object and the image." 40

The hybrid materiality engendered by digital artworks, whether those that explore the autonomy of the machine or those that highlight human-machine collaboration or interdependence, is not just proliferating in art, but is also undergoing extensive redefinition on a theoretical level. Central to this process has been the notion of immaterial materiality put forward by the philosopher Jean-François Lyotard, co-organizer of the exhibition "Les Immatériaux" ("The Immaterials"), held at the Centre Georges Pompidou in Paris in 1985. As Lyotard himself specified, by using the term immaterial, he was "not suggesting that there is no longer any material support", ${ }^{41}$ but rather emphasizing the importance of questioning the meaning and etymology of the term. John Rajchman describes Lyotard's position as follows: "'I]mmateriality' was no longer conceived in terms of freeing concepts or ideas from all materials, but, on the contrary, of shifting the idea of 'materiality' away from that of 'formed matter' (including the 'modernist' distinction between form and content) and towards the 'techno-sciences"'. ${ }^{42}$ Yuk Hui points to a similar shift away from physical matter: "The 'immatériaux' are not immaterial, but rather a new form of material brought about by telecommunication technologies. The new form of material turned against the modern project that produced it and created a rupture with it." ${ }^{43}$ As in the case of conceptual art, Lyotard's new form of material questions the importance of the bounded physical object.

Seeking to describe our contemporary situation, Bernard Stiegler has proposed the term hypermaterialization, the hypermaterial being an aggregate of energy and information where matter and form become indistinguishable and where information undergoes continual change. ${ }^{44}$ Yet as Christiane Paul points out, while Stiegler's term encompasses the processing of information by material technologies, it does not account for the affect that may be contained in such data, "for 'the machines waving back at us', as James Bridle would put it". ${ }^{45}$ Paul suggests instead the concept of neomateriality as a means of describing "the embeddedness of the digital in the objects, images, and structures we encounter [...] and the way we understand ourselves in relation to them". ${ }^{46}$ The interface is of prime importance here: as Alexan- 
der Galloway emphasizes in his book The Interface Effect, it gives access to the world and frames it ideologically and politically. ${ }^{47}$ Neomateriality thus accounts for the digital artworks that I have discussed here, including those that explore ways of "seeing like and being seen through digital devices", ${ }^{48}$ as is the case of the New Aesthetic.

To conclude, the question of the immaterial was up for discussion in the context of both conceptual and digital art, and in each case the claim that art could be immaterial was shown to be unfounded, provoking a renewed focus on the material. Yet the rehabilitation of the material dimension has been a long and complex process in both instances. With regard to conceptual art, the case is still being made for its materiality, as the conference "Conceptualism and Materiality", held as late as 2019 , confirms. In the digital realm, artists are continuing to physicalize the digital, while theorists are devising new forms of materiality that incorporate the digital. The rediscovery of the material thus engendered, in both instances, a turn to a different kind of materiality - a new materiality haunted by the immaterial that testified to the impossibility of completely repressing either.
The repeated emergence of the material in what was thought to be immaterial suggests that material and immaterial are in a state of unresolved tension with respect to each other. In The Parallax View (2006), Slavoj Žižek states that dialectic "constantly shifts perspective between two points between which no synthesis or mediation is possible". ${ }^{49}$ That each point is contained in the other is emphasized by Marcus Pound in his book on Žižek: "Each dialectical pole remains to an extent a continual component of the other such that they perform a mutually critical correction of each other. ${ }^{50}$ It could be argued that the terms material and immaterial are also components of each other and that by acknowledging the presence of the material in what was thought to be immaterial, or vice versa, they too engage in mutual critique, demonstrating that art is always both at the same time.

\section{Notes}

1 Lucy Lippard, Six Years: The Dematerialization of the Art Object from 1966 to 1972 (Berkeley: University of California Press, 1997).

2 Christiane Paul, Digital Art (London: Thames \& Hudson, 2015)

3 "Conceptualism and Materiality. Matters of Art and Politics", The Courtauld Institute of Art, 10-11 October 2019, accessed 27 May 2020, https://courtauld.ac.uk/ event/conceptualism-and-materiality-matters-of-artand-politics.

4 Lippard, Six Years, xi.

5 Lippard, Six Years, vii.

6 Paul, Digital Art.

7 Jacob Lillemose, "Conceptual Transformations of Art: From Dematerialisation of the Object to

Immateriality in Networks", in Curating Immateriality: The Work of the Curator in the Age of Network

Systems, ed. Joasia Krysa (New York: Autonomedia, 2006), 121, accessed 27 May 2020, http://

heavysideindustries.com/wp-content/uploads/2011/01/ Lillemose.pdf.

8 Lucy Lippard and John Chandler, "The

Dematerialization of Art", Art International 12, no. 2 (February 1968): 46.

9 Christian Berger, Introduction, "Conceptualism and Materiality. Matters of Art and Politics", Courtauld Institute of Art, 10-11 October 2019, video, 8:35 9:20, accessed 29 May 2020, https://courtauld.ac.uk/ event/conceptualism-and-materiality-matters-of-artand-politics.

10 Art \& Language, "Unpublished letter-essay from the Art-Language group, Coventry, to Lucy Lippard and John Chandler, 'Concerning the article "The Dematerialization of Art"', March 23, 1968. An excerpt", in Lucy Lippard, Six Years: The Dematerialization of the Art Object from 1966 to 1972

(Berkeley: University of California Press, 1997), 43.

11 Lippard, Six Years, 5.

12 Owen Duffy, "What Was Dematerialization? (And

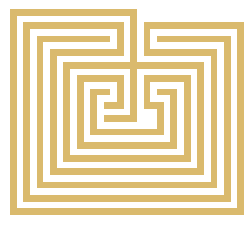

.

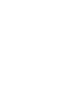

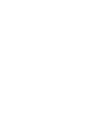


What Does It Mean in the Age of The Cloud?)", Artspace (7 January 2017), accessed 27 May 2020, https://www.artspace.com/magazine/art 101/close look/what-was-dematerialization-54528.

13 Mark Godfrey, Abstraction and the Holocaust (New Haven: Yale University Press, 2007).

$14 \mathrm{lbid}$.

15 Mel Bochner in conversation with Alexis Lowry and James Meyer, Dia Beacon, 8 February 2020, video,

27:55 - 31:46, accessed 29 May 2020, https://diaart. org/media/watch-listen/mel-bochner-in-conversationwith-alexis-lowry-and-james-meyer.

16 Robert Barry, Interview with Arthur R. Rose, in Part VII, Art in Theory 1900-2000: An Anthology of Changing Ideas, eds. Charles Harrison and Paul Wood (Oxford: Blackwell, 2003), 851.

17 Harrison and Wood, "Introduction to Part VII", Art in Theory 1900-2000, 814.

18 Robert Barry cited in Christian Berger,

Introduction, "Conceptualism and Materiality. Matters

of Art and Politics", Courtauld Institute of Art, 10-11

October 2019, video, 11:29, accessed 29 May 2020,

https://courtauld.ac.uk/event/conceptualism-andmateriality-matters-of-art-and-politics.

19 Christian Berger, Introduction, "Conceptualism and Materiality. Matters of Art and Politics", Courtauld Institute of Art, 10-11 October 2019, video, 17:57, accessed May 29, 2020, https://courtauld.ac.uk/event/ conceptualism-and-materiality-matters-of-art-andpolitics.

20 Kavior Moon, “Itinerant Matter: Michael Asher's Air Works", "Conceptualism and Materiality. Matters of Art and Politics", 10-11 October 2019, video, 48:21, accessed 29 May 2020, https://courtauld.ac.uk/event/ conceptualism-and-materiality-matters-of-art-andpolitics.

21 Larisa Dryansky, "Immaterial or Incorporeal? Antimatter and Dematerialization of Art",

"Conceptualism and Materiality. Matters of Art and Politics", 10-11 October 2019, video, accessed 29 May 2020, https://courtauld.ac.uk/event/ conceptualism-and-materiality-matters-of-art-and- politics.

22 Niko Vicario, "Synchronizing Lag: The Materiality of Art's Speed", "Conceptualism and Materiality.

Matters of Art and Politics", video, accessed 29 May 2020, https://courtauld.ac.uk/event/conceptualismand-materiality-matters-of-art-and-politics.

23 Lillemose, "Conceptual Transformations", 123.

24 Jack Burnham, "Systems Esthetics", Artforum 7, no.1 (September 1968): 31.

25 Lillemose, "Conceptual Transformations", 126127.

26 Eve Meltzer, Systems We Have Loved: Conceptual Art, Affect, and the Antihumanist Turn (Chicago: The University of Chicago Press, 2013)

27 lbid., 22.

28 Jack Burnham, Beyond Modern Sculpture: The Effects of Science and Technology on the Sculpture of

This Century (New York: George Braziller, 1968), vii. 29 Ibid.

30 Lillemose, "Conceptual Transformations", 126.

31 Edward Shanken, "Art in the Information Age:

Technology and Conceptual Art", Leonardo 35, no. 4, 433-438 (2002), accessed 2 November, 2020 , https://artexetra.files.wordpress.com/2009/02/ shankenartinfoage.pdf.

32 Duffy, "What Was Dematerialization?".

33 Michael Betancourt, "Automated Labour: The 'New

Aesthetic' and Immaterial Physicality", CTHEORY

(2013), accessed 29 May 2020, http://ctheory.net/ ctheory wp/automated-labor-the-new-aesthetic-andimmaterial-physicality/.

34 See "James Bridle - Waving at the Machines", Web Directions, 5 December 2011, transcript, accessed 3 June 2020, https://www.webdirections. org/resources/james-bridle-waving-at-the-machines/ - transcript.

35 Daniëlle de Jonge, "The Return of Technology as the Other in Visual Practices" (MA thesis,

Utrecht University, August 2013), p. 28, accessed 29 May 2020, https://dspace.library.uu.nl/ handle/1874/283022.

36 Vincent Honoré, "Geographies of
Contamination", 2014, accessed 29 May 2020, http://davidrobertsartfoundation.com/wp-content/ uploads/2013/11/GoC-Leaflet.pdf.

37 Alex Bacon, "Surface, Image, Reception: Painting in a Digital Age", Rhizome, 24 May 2016, accessed June 2020, https://rhizome.org/editorial/2016/may/24/

surface-image-reception-painting-in-a-digital-age/.

38 Ibid.

$39 \mathrm{lbid}$

40 lbid.

41 Jean-François Lyotard, "After Six Months of

Work...(1984)", 30 Years after Les Immatériaux: Art, Science, and Theory, eds. Yuk Hui and Andreas

Broeckmann (Lüneburg: meson press, 2015), 60.

42 John Rajchman, "Les Immatériaux or How to

Construct the History of Exhibitions", Tate Papers 12

(Autumn 2009), accessed 1 June 2020, https://www. tate.org.uk/research/publications/tate-papers/12/ les-immateriaux-or-how-to-construct-the-history-ofexhibitions.

43 Yuk Hui, "Anamnesis and Re-Orientation: A

Discourse on Matter and Time", 30 Years after Les Immatériaux: Art, Science, and Theory, eds. Yuk Hui and Andreas Broeckmann (Lüneburg: meson press, 2015), 181.

44 See Bernard Stiegler, Economie de l'hypermatériel et psychopouvoir (Paris: Mille et une nuits, 2008). 45 Christiane Paul, "From Immateriality to

Neomateriality: Art and the Conditions of Digital Materiality", Proceedings of the 21st International Symposium on Electronic Art ISEA 2015, accessed 3 June 2020, https://isea2015.org/proceeding/ submissions/ISEA2015_submission_154.pdf. 46 Ibid.

47 Alexander R. Galloway, The Interface Effect (Cambridge: Polity Press, 2012).

48 Paul, "From Immateriality to Neomateriality". 49 Slavoj Žižek, The Parallax View (Cambridge, MA: MIT Press, 2006), 4

50 Marcus Pound, Žižek: A (Very) Critical Introduction (Grand Rapids: William B. Eerdmans Publishing, 2008), 92.

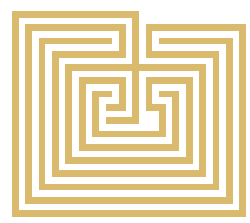


Dr. Rahma Khazam is a researcher, art historian and critic affiliated to Institut ACTE, Sorbonne Paris 1. Her research, which spans the fields of contemporaneity, modernism, image theory and speculative realism, has been published in edited volumes, exhibition catalogues and academic journals. She edited a monograph on the work of the artist Franck Leibovici in 2018. 